\title{
COMPARATIVE ANALYSIS OF SERVE AND SERVE RECEPTION PERFORMANCE IN POOL B OF EUROPEAN MEN'S VOLLEYBALL CHAMPIONSHIP 2015
}

\author{
Raini Stamm ${ }^{1}$, Meelis Stamm ${ }^{2}$, Marko Vantsi ${ }^{1}$, \\ AleksANDER JAIRUS ${ }^{1}$ \\ ${ }^{1}$ School of Natural Sciences and Health, Tallinn University, Tallinn, Estonia \\ ${ }^{2}$ Estonian Defence Forces Headquarters
}

\begin{abstract}
The aim of the study was to analyse the successfulness of tactics of serve and serve reception of the national teams who participated in Pool B of European Men's Volleyball Championship in 2015.

The study included four national teams: Estonia, France, Croatia and Italy. A total of six games and 912 serves were analysed.

Data were collected using the statistics program Data Volley 2007. The data were transferred to Microsoft Excel 2010, which was used for data analysis. Additional statistical analysis was performed using the program SPSS Statistics 21 .

For jump float serve, the most preferable service zone was zone 5. The serves from this zone were also the most dangerous. For power jump serve, the most preferable service zone was zone 1. From this zone the smallest number of faults were made at power jump serve, but also the smallest number of ace serves and serves after which the opponent could not use all attack combinations were performed.

Substitute players who came game only to perform serves showed the same efficiency in jump float serve as starting players. Among the performers of power jump serves, the starting players could perform more ace serves, but there were also more serves after which the opponent could use all attack combinations. Thus, the serve efficiency was relatively similar for both types of players.

Players using the power jump serve were more likely to earn a point with their first serve than the performers of jump float serve. The likeliness of earning a point with the second consecutive serve increased for players using the
\end{abstract}


jump float serve, but remained the same for performers of power jump serve. At power jump serve, service faults occurred more often after timeout than in play, but good serves were hit equally after timeout and in play. At jump float serve, the number of faults was the same after timeout and in play, but good serves, both aces and serves after which was not possible to use all attack combinations, were more often hit after timeout.

Underhand pass was used for receiving float serve almost twice more often than overhand pass, even though the accuracy of the latter was higher.

Keywords: volleyball; serve; serve reception

\section{INTRODUCTION}

In 2015, the Estonian men's national volleyball team had the opportunity to participate in the European Championship. For our national volleyball team, this was the third time to participate in the final tournament. The Estonian national volleyball team finished the European Championship with the $11^{\text {th }}$ place. The current study analysed the performance of the Estonian national team and other teams in the same pool: France ( $1^{\text {st }}$ place), Italy ( $3^{\text {rd }}$ place) and Croatia $\left(15^{\text {th }}\right.$ place). The study concentrated on serve and serve reception. Answers were sought to the following questions:

- Who are more successful - power jump servers or jump float servers?

- Are receivers using overhand pass or underhand pass better at receiving the float serve?

- Do the exchange players who come to hit serves have higher efficiency of serve and do the serves performed after a pause (beginning of a set, technical timeout, coach's timeout, viewing a video replay) have higher efficiency?

- Is serve reception better if the serve is directed at the player, not past the player?

- Do power jump servers or jump float servers hit longer series of serves and how does the efficiency of serve change if the player can perform several serves in succession?

Serve is the only element in volleyball that the player can perform entirely independently. Serve is not performed in cooperation with other players, and it is not impeded by the opposing team. Thus, the players can choose the type of serve they use, how much strength they apply and where they direct the serve [8]. In men's top-level volleyball, three types of serve are used: power jump 
serve, jump float serve and standing float serve [3, 10, 11]. From the 1990s, the share of jump serve in top-level volleyball has remarkably increased [1].

In international-level volleyball the strategy of serve is drawn up considering the strategies of block and defence. One of the aims of serve is to enable one's own players to perform the double block and, thus, to increase the opportunities to play the ball up in defence [13]. Good serve deprives the opposing team the opportunities to use the first tempo [19] and "pipe" attacks (a wave of attack combinations from zones 3-6) [5]. In her book [20], Wise writes that serve is the first element of defence, as a good serve drives the opposing team further from the net, and this facilitates better organisation of block and defence. In principle, good serve in combination with strong blocking and defence strategies makes it very difficult for the opponent to score a point [7].

Earning a point is not the only objective of serve [16]. Marelic and coauthors [9] studied how many points a team should gain in each set using a certain element of the game in order to win a set. The study revealed that 1.6 points per set should be earned directly from serves. In addition to serves from which points are gained directly, a good serve in top-level volleyball should lead the reception of the opposing team further from the net, thus giving them fewer choices at attack [16]. When the opposing team has difficulties in serve reception, their chances to win are smaller [14]. Serve is in strong correlation with scoring of points and the resulting winning of the match [18]. Several studies confirm that teams who are in a losing situation take greater risks at serve, obviously because they have nothing to lose [6]. Marelic and co-authors [9] state in their study of Italian Championship League that the teams who lost a set were more aggressive at serve. This way, they improved their chances for earning a point. With risky serve, the teams attempted to neutralise the opponent's attack and to increase their advantages in block and defence. Risking the serve also creates more service faults. Palao's [11] studies confirm that higher-level teams make fewer unforced errors, including fewer service faults. In addition, it has been found that the team who performs more ace serves also wins games more frequently [19].

\section{MATERIAL AND METHODS}

The study included four national teams participating in European Championship 2015: Estonia, France, Croatia and Italy. A total of six matches were analysed. The teams played in Pool B of the European Championship of 2015. 
All teams held three matches, and a total of 21 sets were played: France 12, Italy 11, Estonia 10 and Croatia 9. The Pool was won by France who won Italy 3:2, Estonia 3:1 and Croatia 3:0. The second place was achieved by Italy who won Estonia and Croatia with the result 3:0. The third place was achieved by Estonia who won Croatia 3:0, and Croatia remained the fourth in the Pool. In total, 912 serves were analysed, 176 of them performed by Croatia, 245 by Italy, 212 by Estonia and 279 by France.

The data for the current study were collected using the statistics program Data Volley 2007, which is used by most national teams and top-level clubs [4]. The program gives an overview of the points won and lost by each player and repetitions of activities; a six-point assessment scale is used for recording of serve and serve reception.

The data were collected by Data Volley either during the game or viewing the video. The statistics of all the games were drawn up by the statistician of the Estonian national team.

The data collected by the Data Volley program gives an overview of the frequency and efficiency of the activities performed in the game and the number of performance errors, but it does not provide information on concrete technical means used in the game. In addition to data collection, descriptive statistics was used, which gives a better overview about the situations of the game and the technical elements used. To collect data for descriptive statistics, videos of the analysed games were used. The camera was placed at the end of the court so that the field of view would include the whole court and service area. This way, the reception zone of each serve was recorded [2].

To find statistical significance, the chi-squated test based on the bivariate frequency table was used. A correlation was considered statistically significant when the value of $\mathrm{p}$ was under 0.05 . Additional statistical analysis was performed using the program SPSS Statistics 21.

\section{RESULTS AND DISCUSSION}

\section{Comparison of power jump serve and jump float serve}

The use of power jump serve and jump float serve differed according to teams. Among Croatia's 176 serves, there were 106 power jump serves and 70 jump float serves, which makes $60 \%$ of power jump serves and $40 \%$ of float serves. Out of the 245 serves of the Italian team, 179 were power jump serves and 66 jump float serves. Thus, power jump serves made up $73 \%$ and float serves $27 \%$. 
The indicators of the Estonian team were similar to those of the Croatian team, i.e. out of 212 serves, 127 were power jump serves and 85 jump float serves, which makes $60 \%$ of power jump serves and $40 \%$ of float serves. France used the greatest number of jump float serves, out of 279 serves, 150 were power jump serves and 129 jump float serves. This makes $54 \%$ of power jump serves and $46 \%$ float serves. In total for all the teams studied, out of 912 serves, $61 \%$ were power jump serves and 39\% jump float serves.

Table 1. Percentage of power jump serve and jump float serve according to teams

\begin{tabular}{lccc}
\hline & $\begin{array}{c}\text { Total number } \\
\text { of serves }\end{array}$ & $\begin{array}{c}\text { Percentage of power } \\
\text { jump serve }\end{array}$ & $\begin{array}{c}\text { Percentage of jump } \\
\text { float serve }\end{array}$ \\
\hline Croatia & 176 & $60 \%$ & $40 \%$ \\
\hline Italy & 245 & $73 \%$ & $27 \%$ \\
\hline Estonia & 212 & $60 \%$ & $40 \%$ \\
\hline France & 279 & $54 \%$ & $46 \%$ \\
\hline Total & 912 & $61 \%$ & $39 \%$ \\
\hline
\end{tabular}

Standing serve has almost disappeared from men's top-level volleyball. This tendency was confirmed by the 2004 study by Agelonidis, which showed that in 1992 the share of jump serve was $20.8 \%$, in 2002 already $99.2 \%$. In the European Championship of 2015, standing serve was not used at all [1].

\section{Efficiency of power jump serve and jump float serve}

Comparison of two types of serve - power jump serve and jump float serve showed that considerably more faults occurred at power jump serve. When the percentage of faults at jump floating serve was $4 \%$, then at power jump serve it was as high as $25 \%$. Power jump serve faults have earlier been studied by Palao (2009), Moras (2008) and Ringmets (2010) in whose studies the percentage of power jump serve faults was $21 \%-25 \%[10,12,17]$. The percentage of faults in our study falls into the same range. When, however, the number of float serve faults is compared with earlier studies, then in Pena's study (2013) the percentage of jump float serve faults was considerably greater, as high as $10 \%$ [15]. More faults occur at power jump serve than at jump float serve; a statistically significant correlation was found between power jump serve and the number of faults $(\mathrm{p}=0.001)$. 
The performers of power jump serve were allowed to risk and this resulted in the greater number of faults. The percentage of ace serves from jump float serve was $3 \%$, from power jump serve, however, $7 \%$. In Moras' study (2008) the percentage of ace serves was 9\% [10]. According to Palao's study (2009) the percentage of ace serves from jump float serve was $2 \%$ [12].

The share of performed serves that did not allow the opposing team to use all attack combinations was equal in the case of both serve types $-39 \%$. This was smaller than in Moras' study of 2008 where the result was $43 \%$ from jump float serve and $46 \%$ from power jump serve [10].

The greatest difference in serve efficiency was noticed when comparing the opposing team's opportunities to use all attack combinations after serve reception. In the case of jump float serve, the share of such serves was $54 \%$, but in the case of power jump serve only $29 \%$. According to Moras' study (2008), in the case of power jump serve, it was possible to use all attack combinations in $25 \%$ of cases. In the case of jump float serve it was not possible to use all attackers in $56 \%$ of cases [10]. In the reception of power jump serve, all attack combinations could be used statistically significantly less frequently $(\mathrm{p}=0.001)$ than in the reception of jump float serve.

Table 2. Efficiency of power jump serve and jump float serve.

\begin{tabular}{lcc}
\hline & Power jump serve & Jump float serve \\
\hline Number of serves & 562 & 350 \\
\hline Share of faults & $25 \%$ & $4 \%$ \\
\hline Negative & $29 \%$ & $54 \%$ \\
\hline Positive & $39 \%$ & $39 \%$ \\
\hline Ace serves & $7 \%$ & $3 \%$ \\
\hline
\end{tabular}

\section{Jump float serve from zones 1, 5 and 6}

When performing the jump float serve from zone 1, it was the least efficient to direct it into zone 5 , as then the opponent could use all attackers in as many as $83 \%$ of serves. Serves into zones 6 and 1 were somewhat more dangerous, and the percentages when it was possible to use all attackers were respectively $63 \%$ and $70 \%$. The share of positive serves or serves after which not all attack combinations could be used was the smallest in the case of zone $1-$ only $11 \%$. It was somewhat better to use zone 5; while serving into this zone, all attackers could not be used in $27 \%$ of cases [10]. When serving into zone 6 , the indicator 
was the best, as high as $37 \%$. However, the greatest number of ace serves were hit into zone $5(6 \%)$ and zone $1(3 \%)$, and no ace serves could be hit into zone 6 .

When serving from zone 6 , there were no significant differences resulting from where serve was directed. No ace serves could be hit from this zone. The share of serves after which the opponents could use all attackers was $61 \%$ when serving into zone $5,67 \%$ when serving into zone 6 and $56 \%$ when serving into zone 1 . The share of serves after which not all attack combinations could be used by opponents were $39 \%$ of serves into zone $5,33 \%$ of serves into zone 6 and $44 \%$ of serves into zone 1 .

When serving from zone 5 , the percentages were relatively similar regardless where the serve was directed; aces were hit 9\% into zone 5, 4\% into zone 6 and $5 \%$ into zone 1 . All attackers could be used in $49 \%$ of cases when serving into zone 1,43\% when serving into zone 6 and $44 \%$ when serving into zone 5 . All attackers could not be used in $46 \%$ of cases when serving into zone 5, 53\% when serving into zone 6 and $47 \%$ when serving into zone 1 .

When serving from zones 5 and 6 , the percentages were relatively similar regardless into which zone the serve was directed. The indicator was different only when serving from zone 1 , where the serve along the boundary was the most inefficient.

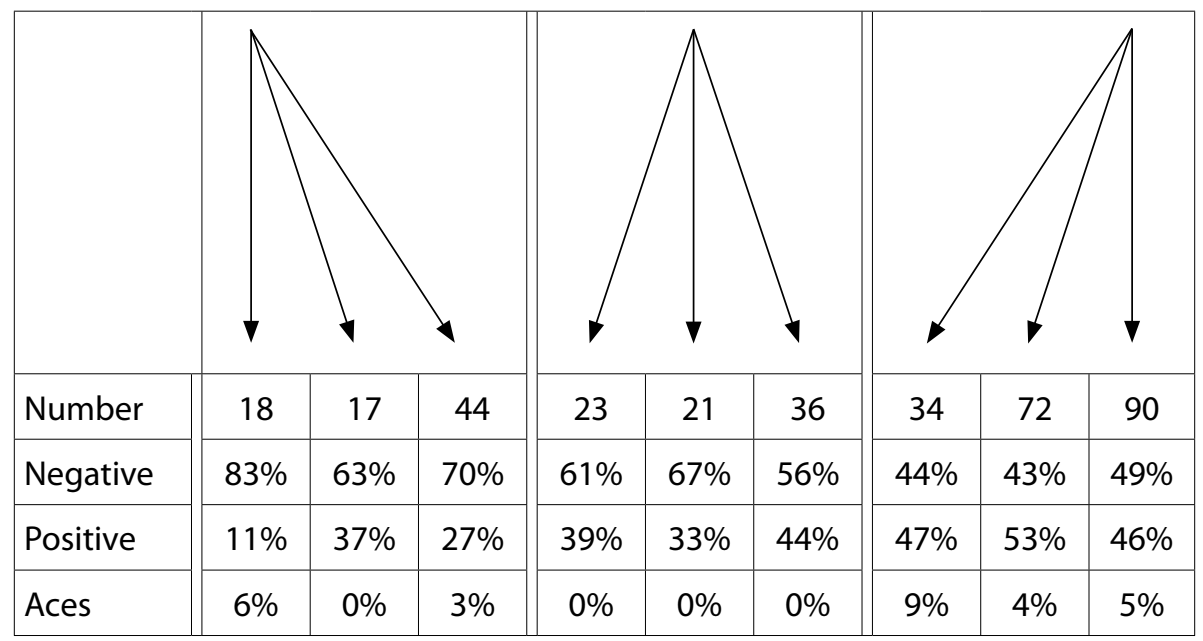

Figure 1. Jump float serve from zones 1, 6 and 5 into different zones. 


\section{Power jump serve from zones 1, 5 and 6}

Serves from zone 1 were relatively similar regardless the zone into which the serve was hit. From all the serves from zone 1, ace serves into zone 1 constituted $9 \%$, into zone $6-7 \%$, and into zone $5-8 \%$. The serves after which not all attack combinations could be used also had a similar percentage, regardless into which zone the serve was targeted. When serving into zone 1 , the indicator was somewhat higher $-59 \%$. When serving into zones 6 and 5 , the percentages were relatively equal $-49 \%$ and $51 \%$ respectively. Thus, the serve is somewhat more dangerous when it is hit along the long diagonal than along the short diagonal or straight. When serving into zone 1 , the share of negative serves after which all attack combinations could be used was $31 \%$. In zones 5 and 6 , the corresponding indicators were higher - after $44 \%$ of serves hit into zone 6 and $41 \%$ into zone 5 , all attack combinations could be used.

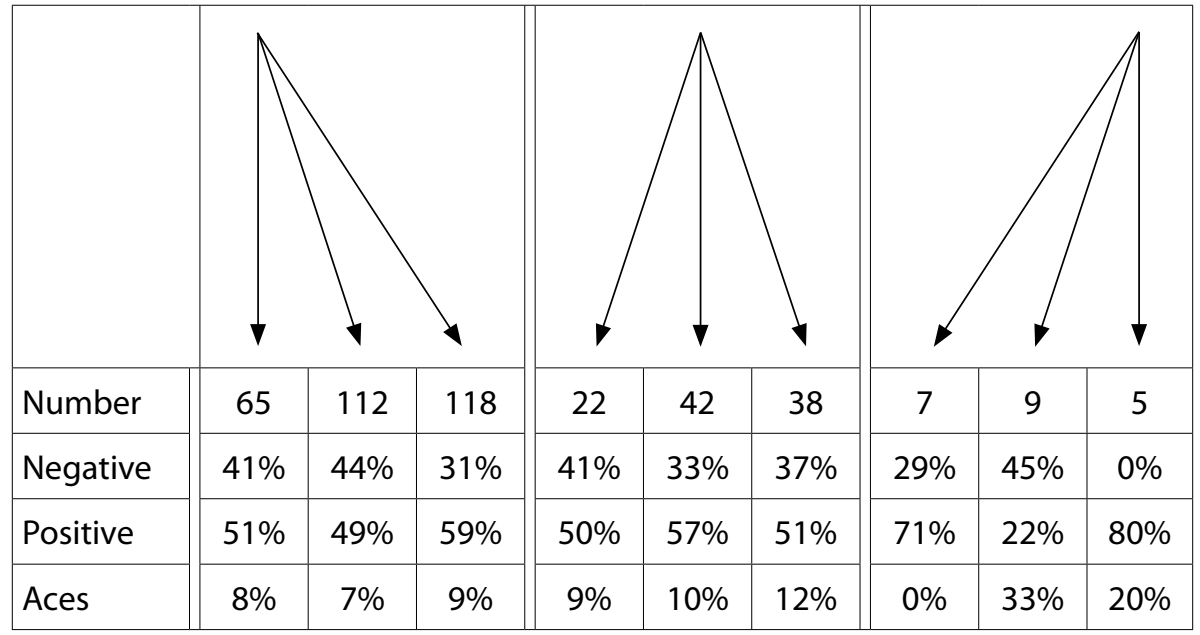

Figure 2. Power jump serves from zones 1, 6 and 5 into different zones

Like in the case of jump float serve from zone 6, the efficiency of power jump serve performance did not depend on the zones into which the serve was targeted. The efficiency of serve into all zones was relatively similar. The percentage of ace serves was $9-12 \%$, positive serves $50 \%-57 \%$ and negative serves $33-41 \%$. As no long diagonal can be hit from 6 , the efficiency of serve is relatively similar, regardless where serve is targeted. 


\section{Exchange players' efficiency of serve}

Exchange players who came to the court only to perform serves did not surpass the starting players by their efficiency of serve. In the case of jump float serve, the indicators were similar to starting players. While the starting players on the court hit an average of $4 \%$ of ace serves, the exchange players failed to hit them. Starting players had $4 \%$ of service faults and exchange players $5 \%$. The percentages of positive and negative serves were also relatively similar - starting players had $39 \%$ of positive serves and exchange players $38 \%$. Starting players hit $53 \%$ of negative serves and exchange players $57 \%$. Very similar percentages show that exchange players were not better servers than starting players.

When power jump serve performers were compared, the number of service faults was equal in both exchange players and starting players. Both had $25 \%$ of service faults. Like float servers, the exchange players performing power jump serves did not hit any ace serves. Starting players were more successful, hitting $8 \%$ of ace serves. The percentage of negative serves was somewhat higher in starting players with $29 \%$; in exchange players it was $20 \%$. The percentage of positive serves was $38 \%$ in starting players and $55 \%$ in exchange players. Although the difference seems to be great, it should be taken into account that starting players performed more ace serves. Thus, exchange players performed more positive serves and fewer ace serves than starting players. In conclusion, the efficiency of exchange players performing power jump serve was similar to that of starting players.

\section{Serve series in power jump serve and jump floating serve}

When performing the serve, the aim of the team is to earn a point. In conclusion, it is of no significance whether the point is earned directly form the serve or some following activity. The serve is the first element that determines the further achievement of the point, and therefore, successful serve is of utmost importance for gaining the following point. If earning a point from power jump serve and jump float serve is compared, the performers of power jump serve were more efficient, being successful in $36 \%$ of cases. The corresponding indicator for jump float serve was $31 \%$. This means that, despite the greater number of faults at power jump serve, $5 \%$ more points could be earned than from jump float serves.

At power jump serve, two points in succession were earned in $13 \%$ cases, at float serve the corresponding indicator was $14 \%$. Thus, when reaching the second serve, the probability of gaining a point was greater at float serve than at power jump serve. From the second successive serve, a point was earned 
from $41 \%$ of float serves and $36 \%$ of power jump serves. Thus, when performing a second successive serve, in the case of jump float serve, the probability of gaining a point was greater than from the first serve. In the case of power jump serve, the probability of earning a point neither increased nor decreased.

When a player reached the third serve, the probability of earning a point from power jump serve decreased to $28 \%$. In the case of jump float serve, the frequency of gaining a point was similar to performing the first serve. Thus, a point was earned in $35 \%$ of cases. The fourth serve was reached seldom, and there were too few cases to draw any conclusions.

Table 3. Serve series at jump float serve and power jump serve

\begin{tabular}{lcc}
\hline & Power jump serve & Jump float serve \\
\hline First serves performed & 260 & 229 \\
\hline Percentage of reaching the second serve & $36 \%$ & $31 \%$ \\
\hline Percentage of reaching the third serve & $13 \%$ & $14 \%$ \\
\hline Percentage of reaching the fourth serve & $4 \%$ & $4 \%$ \\
\hline Percentage of reaching the fifth serve & $2 \%$ & $1 \%$ \\
\hline
\end{tabular}

\section{Serve reception according to teams}

The best team at reception was France who had 55\% of positive receptions in three games. The percentages of positive receptions by the other three teams were relatively similar - Croatia $45 \%$, Estonia and Italy $42 \%$. The smallest number of ace serves were also hit to France - 3\% of all serves. Considering ace serves, the following was the Estonian national team with $6 \%$, then Italy with $9 \%$ and Croatia with $10 \%$. France had the smallest percentage of negative reception $-42 \%$, followed by Croatia with $45 \%$, although the greatest number of ace serves was also hit to them. Italy had $49 \%$ of negative reception and Estonia 52\%. Thus, France was clearly the best at reception; they allowed the smallest number of aces to be hit to them and received the greatest number of serves positively. The reception of Estonia, Italy and Croatia was nearly equal; Estonia had more negative receptions, but allowed fewer ace serves to be hit than Croatia and Italy.

If the teams' reception of power jump serves and jump floating serves is compared, the smallest number of ace serves were hit to France. Only 5\% of power jump serves were allowed to be hit as ace serves, and at float serve reception, they did not give the opponents any points directly from reception. 
Table 4. Efficiency of serve reception according to teams

\begin{tabular}{|c|c|c|c|c|}
\hline & Croatia & Italy & Estonia & France \\
\hline \multicolumn{5}{|c|}{ Jump float serve reception } \\
\hline Number of jump float serve receptions & 91 & 104 & 77 & 65 \\
\hline Faults of float serve reception & $8 \%$ & $2 \%$ & $4 \%$ & $0 \%$ \\
\hline Negative float serve reception & $43 \%$ & $47 \%$ & $40 \%$ & $29 \%$ \\
\hline Positive float serve reception & $49 \%$ & $51 \%$ & $56 \%$ & $71 \%$ \\
\hline \multicolumn{5}{|c|}{ Power jump serve reception } \\
\hline Number of power jump serve receptions & 97 & 96 & 99 & 127 \\
\hline Faults of power jump serve reception & $12 \%$ & $17 \%$ & $8 \%$ & $5 \%$ \\
\hline Negative power jump serve reception & $48 \%$ & $52 \%$ & $61 \%$ & $49 \%$ \\
\hline Positive power jump serve reception & $40 \%$ & $31 \%$ & $31 \%$ & $46 \%$ \\
\hline \multicolumn{5}{|c|}{ Serve reception } \\
\hline Number of serve receptions & 188 & 200 & 176 & 192 \\
\hline Faults of serve reception & $10 \%$ & $9 \%$ & $6 \%$ & $3 \%$ \\
\hline Negative reception & $45 \%$ & $49 \%$ & $52 \%$ & $42 \%$ \\
\hline Positive reception & $45 \%$ & $42 \%$ & $42 \%$ & $55 \%$ \\
\hline
\end{tabular}

The Estonian team allowed $4 \%$ of jump float serves and $8 \%$ of power jump serves to be served as ace serves. Croatia was somewhat weaker than Estonia in both aspects - at the reception of jump float serve, they allowed $8 \%$ of aces and from power jump serve $12 \%$. Italy differed greatly, as it was very good at the reception of float serves. They allowed to hit only $2 \%$ of aces, but at power jump serve, the opponents could directly get a point from $17 \%$ of receptions. While to France, Estonia and Croatia, 4-5\% more percentage points of aces were hit from power jump serves than from float serves, then in the case of Italy, the difference was as high as 15 percentage points. At positive reception, the best was France whose percentage of positive reception of float serve was $71 \%$ and that of power jump serve $46 \%$. Both indicators were better than those of the other teams. Croatia was the weakest at float serve reception, receiving the serve positively in $49 \%$ of cases, but, at power jump serve reception, it was clearly better than Estonia and Italy, receiving positively $40 \%$ of all power jump serves. Thus, their positive reception of power jump serve decreased the least compared to jump float serve. The Estonian national team received positively 
$56 \%$ of jump float serves but only $31 \%$ of power jump serves. Thus, in float serve reception, Estonia was the second after France, but in power jump serve reception shared the last place with Italy. Italy's percentage of positive reception of float serve was $51 \%$ and of power jump serve $31 \%$, thus being among the two weakest teams in both indicators.

\section{Serve reception with underhand and overhand pass}

For receiving float serve, underhand pass was used almost twice more often than overhand pass, even though the accuracy of the latter was higher. From all receptions with underhand pass, $4 \%$ were aces, while from receptions with overhand pass this percentage was only $2 \%$. There was a very great difference in receptions that could not be attacked. While in the case of underhand pass, this indicator was $9 \%$, then with overhand pass $-1 \%$. This shows that with underhand pass receptions, attack could not be arranged in $13 \%$ of cases, but with overhand pass receptions, the same indicator was only $3 \%$. There were statistically significantly more underhand pass receptions that could not be attacked than overhand pass receptions $(\mathrm{p}=0.018)$. The number of receptions that could be continued into attacks, but where it was not possible to use all attackers was relatively similar in the case of both underhand and overhand passes. With underhand pass, the corresponding indicator was 36\% and with overhand pass $32 \%$. The number of receptions where all attack combinations could be used was also significantly greater in the case of overhand pass receptions. With overhand pass reception, all attackers could be used in $65 \%$ of receptions, but in the case of underhand pass receptions this indicator was 51\%. A statistically significant correlation was found between overhand pass reception and the possibility of using all attack combinations $(\mathrm{p}=0.012)$.

Table 5. Efficiency of serve reception with underhand and overhand pass

\begin{tabular}{lcc}
\hline & $\begin{array}{c}\text { Reception with } \\
\text { underhand pass }\end{array}$ & $\begin{array}{c}\text { Reception with } \\
\text { overhand pass }\end{array}$ \\
\hline Number of receptions & 213 & 121 \\
\hline Reception errors & $4 \%$ & $2 \%$ \\
\hline Could not attack & $9 \%$ & $1 \%$ \\
\hline Could not use all attackers & $36 \%$ & $32 \%$ \\
\hline Could use all attackers & $51 \%$ & $65 \%$ \\
\hline
\end{tabular}




\section{CONCLUSIONS}

Statistically significantly more service faults occurred at power jump serve than at jump floating serve $(\mathrm{p}=0.001)$. Nonetheless, power jump serve is more dangerous and in the reception of this serve, all attack combinations could be used statistically significantly less frequently $(\mathrm{p}=0.001)$, than in the reception of jump float serve.

There were statistically significantly more receptions with underhand pass which could not be followed by an attack than receptions with overhand pass $(p=0.018)$. In reception with overhand pass, all attack combinations could be used statistically significantly more often than in the case of underhand pass reception $(\mathrm{p}=0.012)$.

In jump float serve, the indicators of serve efficiency were very similar in starting players and exchange players who had come to serve. Starting players who performed power jump serves hit more ace serves, but exchange players had fewer serves, after which all attack combinations could be used. Thus, exchange players were not better servers than starting players.

The number of power jump serve number faults increased after timeout, but the serve did not become more dangerous. Jump float serve after timeout was statistically significantly more dangerous than the serve hit in the game situation $(\mathrm{p}=0.006)$.

Statistically significantly more serves that directly earned a point were not hit directly towards the receivers, but they had to move to the left or to the right during serve reception ( $\mathrm{p}=0.001)$. Serves, which were targeted directly at a player were statistically significantly more often received so that all attack combinations could be used than the serves that were directed to the right or left of the receivers $(\mathrm{p}=0.001)$.

Players using the power jump serve were more likely to earn a point with their first serve than the performers of jump float serve. The likeliness of earning a point with the second consecutive serve increased for players using the jump float serve, but remained the same for performers of jump power serve.

\section{REFERENCES}

1. Agelonidis Y. (2004). The jump serve in volleyball: From oblivion to dominance. Journal of Human Movement Studies 47(3), 205-213.

2. Afonso J., Esteves F., Araújo R., Thomas L., Mesquita I. (2012). Tactical determinants of setting zone in elite men's volleyball. Journal of Sport Science and Medicine, 11, 64-70. 
3. Benerink N.H., Bootsma R.J., Zaal F.T.J.M. (2015). Different tempo bases for body and arm movements in volleyball serve reception. Scandinavian Journal of Medicine \& Science in Sports, 25(5), 603-609.

4. Data Project sport software (2012). Software for the Scouting and Analysis of Volleyball Matces.

5. Fellingham G., Hinkle L., Hunter I. (2013). Importance of attack speed in volleyball. Journal of Quantitative Analysis in Sport, 9, 87-96.

6. João P., Leite N., Mesquita I.J. (2010). Sex differences in discriminative power of volleyball game-related statistics. Perceptual and Motor Skills, 111(3), 893-900.

7. López J.P. (2013). Analysis of the Serve as a Performance Factor in High-Level Volleyball and Beach Volleyball. Doctoral thesis, University of Barcelona.

8. López-Martinez A.B., Palao J.M. (2009). Effect of Serve Execution on Serve Efficacy in Men's and Women's Beach Volleyball. International Journal of Applied Sports Sciences, 21(1), 1-16.

9. Marelić N., Rešetar T., Zadražnik M., Đurković T. (2005). Modelling of situation parameters in top level volleyball. $4^{\text {th }}$ International Scientific Conference on Kinesiology, Opatija, Croatia.

10. Moras G., Buscà B., Peña J., Rodríguez S., Vallejo L., Tous-Fajardo J., Mújika I. (2008). A comparative study between serve mode and speed and its effectiveness in a high-level volleyball tournament. Journal of Sports Medicine and Physical Fitness, 48(1), 31-16.

11. Palao J.M., Santos J.A., Ureña A. (2004). Effect of team level on skill performance in volleyball. International Journal of Performance Analysis in Sport, $4(2), 50-56$.

12. Palao J.M., López P.M., Ortega E. (2009). Techniques used and efficacy of volleyball skills in relation to gender. International Journal of Performance Analysis in Sport, 9(2), 281-293.

13. Papageorgiou A., Spitzley W. (2003). Handbook for competitive volleyball. Meyer \& Meyer Sport (UK) Ltd.

14. Patsiaouras A., Moustakidis A., Charitonidis K., Kokaridas D. (2011). Technical skills leading in winning or losing volleyball matches during Beijing Olympic Games. Journal of Physical Education and Sport, 11(2), 149-152.

15. Peña J., Buscà B., Moreno-Galcerán D., Bauzà J. (2013). The effect of aerodynamic drag in the service speed on high-levels men's volleyball. 18 Congress of the ECSS, Barcelona.

16. Quiroga M.E., Carcia-Manso J.M., Rodrigez-Ruiz D., Sarmiento S., De Saa Y., Moreno M.P. (2010). Relation between in-game role and service characteristics in elite women's volleyball. Journal of Strength and Conditioning Research, 24(9), 2316-2321.

17. Ringmets R. (2010). Audentese Võrkpalliklubi Selver Tallinn pallingu ja pallingu vastuvõtu analüüs Eurosarja mängudel aastatel 2008-2010. Bachelor thesis, Tallinn University. 
18. Silva M., Lacerda D., João P.V. (2014) Game-related volleyball skills that influence victory. Journal of Human Kinetics, 41, 173-179.

19. Zetou E., Moustakidis A., Tsigilis N., Komninakidou A. (2007). Does Effectiveness of Skill in Complex I Predict Win in Men's Olympic Volleyball Games? Journal of Quantitive Analysis Sports, 3(4), DOI: 10.2202/1559-0410.1076.

20. Wise M. (2002). The volleyball coaching bible. Champaign, IL: Human Kinetics.

\author{
Address for correspondence: \\ Raini Stamm \\ Tallinn University \\ School of Natural Sciences and Health \\ Narva street 29, 10120 Tallinn, Estonia \\ E-mail: raini.stamm@tlu.ee
}

